\title{
On Site Therapy Services: Access to Care in Chronic Trauma
}

\author{
Shonda Lankford, OTD, MS, OTR/L \\ Helping Hands Therapy, United States
}

Doi: 10.19044/ejes.s.v6a10

URL:http://dx.doi.org/10.19044/ejes.s.v6a10

\begin{abstract}
Chronic poverty presents components of chronic trauma with one major deficit being lack of access to needed quality health care services. Often needed therapeutic services are not available and when available, challenges exist with time or travel constraints of therapists. Students who need therapeutic services such as occupational, physical or speech therapy can fail to thrive in academic expectations if supportive therapy is not provided. Integration of mental health therapy on-site with schools via regional community health organizations has proved effective. A comparative integration of physical health care services was instituted by Helping Hands Therapy to promote access of care for students living in underserved rural poverty areas with key focus on students in special needs programs. The approach rendered benefit to both school districts and students served in modalities of occupational, physical, and speech therapy. Contextual challenges continue to present in commonality with other on-site interventions such as recruitment of therapists, management of time and travel constraints, and increase of parental and caregiver involvement. Further research is indicated for ways to meet these challenges.
\end{abstract}

Keywords: School-based therapy services, access to health care in poverty.

\section{Introduction:}

Occurrence of trauma, either acute or chronic can disrupt routine access to life supporting services such as health care. This disruption can be especially detrimental when individuals have some dependency on such services for quality of life. Ullery, Gonzalez, and Katz (2016) noted the importance of child development on a stable, healthy, and nurturing life experience (p. 403) and indicated several factors that can frame deficit in development such as poverty, presence of crime, and lack of access to applicable and appropriate health-care or education. 
Ullery, et al. (2016) discussed the many limiting experiences that impede successful development in the chronic trauma of poverty. Some examples are communities with high rates of violence or abuse such as substance or personal abuse and dependence on external financial sustenance such as governmental programs. These experiences were supported by many notations of research to adversely affect academic performance of youth within that chronic trauma state of poverty.

Abulof (2017) reminds us of continuing to use Maslow's Hierarchy of Needs as a lens with which to view both life problems and resolutions for humans. Abulof reflected that "we cannot explain social actions without understanding human motivations" (p. 508). Though discourse continues on validity of application in growing societal needs, a premise remains that survival needs of the physical man undergird more esoteric needs such as selfactualization. The foundational level of human need such as food, water, shelter, and safety are most impacted by trauma.

Brendtro and Mitchell (2014) discussed a shift in research and practice from "evidence-based practice" to "practice-based evidence" - a shift in focus on practicing to meet a person's needs (p.5). Framing this within Maslow's Hierarchy of Needs would encourage attention to foundational needs as initial focus of practice. Practitioners of Christianity point to the teachings of Jesus Christ to help meet basic human needs as a foundation for also addressing spiritual needs (Matthew 26, The Holy Bible) Brendtro and Mitchell concluded that the evidence in practice that carries value is the efficacy of impact of effort on meeting needs.

\section{Literature Review}

To understand efficacy of taking intervention into the school setting, it is important to understand nuances of need as framed by chronic trauma. Chronic trauma that has ongoing global impact in large numbers is the trauma of poverty. While the United States might be considered a nation with affluence, a recent report indicated that one in eight Americans live in poverty (US Census Bureau, 2018). According to resources such as The World Bank, nearly half of the world's population struggle to meet these foundational needs (The World Bank, 2018). Nuances of need include not only the presence of need such as health issues, but also how those needs can be met and are being met - as well as deficits in access to sources for meeting needs. As the intervention discussed has focus on access to sources for meeting needs, the literature review is also focused on that.

\section{Health Care Deficits in Poverty}

Persons living in poverty have multiple facets of need and multiple venues of meeting those needs or not. Roelen (2017) observed that often 
income is viewed as the marker of level of access to resources for meeting needs, such as access to provision of health care. Roelen notes that having sufficient income with which to purchase resources such as needed health care does not equate to receipt of satisfactory resolution of needs. An example was a study with children in Ethiopia and Vietnam that revealed greater risk for multidimensional poverty for children living in rural areas (p. 514),

Roelen (2017) addressed additional factors that matter with consideration of income as a marker for needs. One study participant noted that a more affluent family might not practice child-rearing to promote wellbeing, such as choice of diet, practice of sanitation, or activities for children in the family. Another participant noted the impact of personal will or desire, such as a child who had excellent academic performance, though poor.

Markers of poverty can vary across demographic settings, but some common markers dictate presence of chronic trauma such as low income generation, dependence on governmental assistance, deficit in available resources to meet needs, lowered quality of resources that are available, and elevated presence of crime. Jacoby, Tach, Guerra, Wiebe, and Richmond (2017) noted that these inequities in provision of resources and presence of environmental stressors seemingly contribute to increased presence of some chronic disease issues for both adults and children. This was even with study partiipant perceptions that their health status met or exceeded national norms - norms that are still unhealthy in comparison with other similar nations (Wolf \& Aron, 2013). Jacoby, et al used focus groups, assessment instruments, and participant activity mapping and narratives to explore health status and perceptions of well-being among residents of a housing-plus program in Philadelphia, PA, USA for a two year period.

\section{Needs in the Midst of Trauma}

Daily attention to meeting personal needs tends to become routine as people eat, sleep, and tend to hygiene habitually. Carroll, Arkin, Seidel, and Morris (2009) noted that needs tend to direct restoration of a person to wellbeing when satisfaction of needs is disrupted. They indicate that contextual factors such as the presence of trauma can change priority of attention to needs satisfaction.

In a revised look at Maslow's Hiearchy of Needs, per Carroll, et al. (2009) these can be regrouped into Security and Enhancement needs, whereby needs such as self-esteem and self-actualization were considered growth needs (p. 374). In a study between college students who had experienced trauma events and those who had not, Carroll, et al. concluded that helping interventions need to include awareness of the stronger influence of security concerns in a present life situation as compared to capacity to focus on growth with enhancement needs. Thus, the chronic trauma of poverty could foster 
continual focus on security needs such as support and resolution of health issues to the possible detriment in focus on needs such as self-esteem or selfactualization.

Barnett, Cleary, Butcher, and Jankowski (2019) related the crucial impact that trauma had on needs of children served by departments of child welfare, especially in concerns with placement in foster or adoptive homes. In a study with 512 foster/adoptive parents, Barnett, et al. concluded the necessity of a core of trauma-informed practice to provide efficacy of care with children. This mode of practice was described as "recognition and response to impact of trauma on their consumers through screening for trauma exposure and symptoms, use of appropriate evidence-based assessment and treatment, education of consumers, promotion of efforts toward resilience, and collaboration with other child-service systems" (p. 74).

\section{Intervention for Access through Schools}

The school nurse has long been a general health-care resource within the school setting offering first-aid attention, help with medication administration for students with daily needs for that while at school, and consultation for networking with health-care resources outside the school. Often school district funding necessitated the sharing or school nurse resources across multiple schools - a school nurse might actually be on site only one or two days a week.

Brown and Bolen (2003) affirmed the difficulty of access to quality health care for many students due to barriers such as availability of needed services, transportation to and from locations of service provision, and deficiency in funds or adequate insurance to cover services. Brown and Bolen shared the onset of School-based health care centers to primarily lessen occurrence of teen pregnancy. Some benefits of these centers were present for students, families, and schools. Students could receive attention for chronic disease issues as well as preventive and health-promotion support Parents did not have the challenge of juggling work demands and getting children to a health-care provider. Schools had students present and less burdened with distraction of unmet health needs.

As students spend more time in the school setting, there is also a growth in school engagement with the whole child. Power, McGoey, Heathfield, and Blum (1999) noted increased need for accomodation with in the school setting of support for needs that serve as barriers to efficacy in education when those needs were not met. An example is inclusion of accomodataion for students with disabilites, both mental and physical. As these needs are accomodated within the school setting, schools reach more children with the value of education. 
Transportation of health care services for students to the school setting has long been present with Community Mental Health agencies in which day treatment specialists, mental health therapists, and case managers have collaborated with schools to work with student clients in the context of the school setting. Crisp, Gudmundsen, and Shirk (2006) developed the Adolescent Mood Project to help diminish the gap between need for receipt of mental health services with the issue of depression through provision of services within a school setting (p. 290.) Rationale included close proximity to students who needed service, schools as valued and trusted members of communities, and a setting where students are already served in the sense of „the whole child.“ Preliminary study of the project indicated positive reception by school personnel in evidence of amelioration of academic distractors and increase in academic focus and success by students served by the project..

\section{Intervention Methodology}

While integration of mental health intervention has been in schools for a couple of decades, efforts are increasing to also integrate other therapies within the school setting. Based on observed need and deficit in access for services in Occupational Therapy, Physical Therapy, and Speech Therapy, a program called Helping Hands Therapy was developed to serve areas of chronic trauma through poverty in 18 counties throughout rural Alabama. The core philosophy of care was to take therapy to the person in need to enhance access of care in routine and comfortable setting such as a school. In addition to some provision of therapy in an outpatient setting, therapy is taken to persons in skilled nursing facilities, and schools. For many of the school districts served, a focus is on service to students with special needs.

Key considerations for implementation of the three therapy services with a school system were knowledge of student needs, knowledge of state guidelines for school-based therapeutic intervention, and effective match of therapist to child. Upon decision of a school system to contract for the therapy, a team is planned to serve the unique needs of the school and includes professionals of licensed therapists, caseload coordinator, scheduler, client relations manager, rehabilitation manager, and a business manager. The Helping Hands Therapy Program services to a school district are outlined in table 1 .

Table 1. Key Services to School Districts

\begin{tabular}{lll}
\hline Service & Benefit for School District & $\begin{array}{l}\text { Benefit for Student } \\
\text { Served }\end{array}$ \\
\hline Employment of Therapists & $\begin{array}{l}\text { Administrative and financial details } \\
\text { such as taxes, licensure } \\
\text { management, and employee }\end{array}$ & $\begin{array}{l}\text { Provision of local } \\
\text { available therapy } \\
\text { service to meet student } \\
\text { need. }\end{array}$ \\
\hline
\end{tabular}




\begin{tabular}{llll}
\hline & & $\begin{array}{l}\text { benefits are not a burden on the } \\
\text { district. }\end{array}$ & \\
\hline $\begin{array}{l}\text { Therapy scheduled } \\
\text { according to student }\end{array}$ & $\begin{array}{l}\text { Appropriate therapy is scheduled to } \\
\text { fit student need without burden on } \\
\text { Individualized Education } \\
\text { Program (IEP) }\end{array}$ & $\begin{array}{l}\text { Student lequirements are met } \\
\text { school leadership and teachers to }\end{array}$ \\
\hline $\begin{array}{l}\text { Assumption of liability } \\
\text { costs }\end{array}$ & $\begin{array}{l}\text { School district does not have } \\
\text { burden of management of liability } \\
\text { costs }\end{array}$ & $\begin{array}{l}\text { Awareness of liability } \\
\text { issues promotes best } \\
\text { sractice care for } \\
\text { students }\end{array}$ \\
\hline $\begin{array}{l}\text { Integration of Parent } \\
\text { Consultation }\end{array}$ & $\begin{array}{l}\text { Promotion of team approach } \\
\text { between school, family of student, } \\
\text { and therapy provider }\end{array}$ & $\begin{array}{l}\text { Enhanced development of whole } \\
\text { child support }\end{array}$ \\
\hline On-site consultation & $\begin{array}{l}\text { Therapists are aware of provision in } \\
\text { student classroom settings and }\end{array}$ & $\begin{array}{l}\text { Rapport with serving } \\
\text { therapist in a natural } \\
\text { teacher challenges for support of } \\
\text { student environment }\end{array}$ \\
& $\begin{array}{l}\text { student needs } \\
\text { Integration of serving therapist with } \\
\text { the school support team for each } \\
\text { student. }\end{array}$ & \\
\hline
\end{tabular}

\section{Process of Intervention}

Intervention design must not only be effective per outcomes and fit with the scope of life at school, but must also be acceptable and satisfactory to parents or caregivers. Slade, Eisenhower, Carter, and Blacher (2018) analyzed parental satisfaction factors with students' Individualized Education Program (IEP) compents - the document that outlines all services to be provided to a student enrolled in a school Special Education Program.

Slader, et al. Noted four crucial aspects for parental satisfaction. Three of these are core provisions of contracted service between student's family, the school, and the therapy provider. These aspects are (1) services provided, (2) perceived level of agreement between the IEP document and services actually provided, and (3) effectiveness of the IEP team - which includes the team members from the contracted service provider.

Intervention begins with contracting of services within a school setting based on collaboration and completion of necessary administrative and planning documentation by Helping Hands Therapy, the school, and the student's parents or care-givers. As the therapeutic services are for medically diagnosable conditions, a physician's orders must be included for therapy services to be contracted.

Intervention therapy is provided at the site of the school per details as outlined by the physian orders and the scheduling required in the student's IEP from the school. A seamless support team is present throughout the intervention time frame as Helping Hands Therapist, school professional such 
as a school nurse or Special Education Coordinator, and the Helping Hands Case Manager for the student, work with the student and family to best support the identified needs. The support offered to a student in the school setting is the same as receipt of services at an off-campus location, yet gives the convenience of service at school. Therapy is terminated upon physician's orders for the student patient to be discharged from therapy.

An example of intervention per the IEP is integration of physical therapy with children who have Autism. Geslak (2016) shared five benefits of physical exercise which could be promoted through physical therapy - body image, posture, motor coordination, muscular fitness, and cardiovascular fitness (p. 35). Geslak noted that physical therapy is often a component of IEPs for many students.

Another example of intervention per an IEP is integration of occupational therapy for students per a disability. Clark, Jackson, Polichino, and DeLany (2011) described occupational therapy interventions that could be included in an IEP - performance skills such as sensory-perceptual or social, performance habits such as development of routines, and activity demands such as required actions or body functions. An intervention component that has been delivered via Helping Hands is to teach students with disabilities coordination skills needed for activities such as feeding themselves or using a computer.

\section{Conclusion}

Chronic poverty serves as a framework for chronic trauma, especially for children and adolescents. Increased risk factors are daily present such as presence of community or family violence, deficit with income or legal means for attainment of needed income, lack of needed resources, and often substandard of resources that may be present. Protective factors for building resilience are often diminished through lack of awareness of potential positive resources or lack of inner locus of control.

Limitations of the approach have been identified as contextually common with provision of other services to chronic poverty locales. Recruitment of therapists can be challenged by potential therapy jobs with more enticing benefits and growing need for provision of these therapies across all demographic areas. Travel time between schools served can infringe on time available to treat. Lastly, while both Helping Hands Therapy and the school districts consistently encourage and seek parental and caregiver involvement and follow-through, there is deficit in this. Smakowski (1998) noted that common components of poverty were ,parental unemployment, single-parent households, high parental stress, and lower educational attainment" - all of which serious distract parent availability or interest with engagement in the therpeutic service delivery of their children. 
Intervention can make a positive difference where needed services are offered within natural contexts for children in poverty such as a school setting. Contracted provision of service such as occupational, physical or speech therapy can provide benefit to both school districts and the students served on site within district facilities. While contextual challenges continue to exist, growth in on-site intervention programs can occur through persistence and sharing of results with applicable professional communities. Further research is needed on methods with which to meet these contextual challenges.

\section{References:}

1. Abulof, U. (2017) Why we need Maslow in the twenty-first century. Society, 54, 5088-509.

2. Barnett, E. R., Cleary, S. E., Butcher, R. L., \& Jankowski, M. K. (2019). Children's behavioral health needs and satisfactionand commitment of foster and adoptive parents: Do trauma-informed services make a difference? Psychological trauma: Theory, research, Practice, and Policy, 11(1), 73-81.

3. Brendtro, L.K. \& Mitchell, M.M.(2014). Powerful outcomes: Delivering what works. Reclaiming Youth and Children, 22(4), 5-11.

4. Brown, M.B. \& Bolen, L. M. (2003). School-based health centers: Strategies for meeting the physical and mental health needs of children and families. Psychology in the Schools, 40(3), 279-287.

5. Carroll, P.J., Arkin, R.M., Seidel, S. D., \& Morris, J. (2009). The relative importance of needs among traumatized and non-traumatized samples. Motivation \& Emotion, 33, 373-386.

6. Clark, G.F., Jackson, L, Polichino, J, \& DeLany, J.V. (2011). Occupational therapy services in early childhood and school-based settings. Journal of Occupational Therapy, 65, S46-54.

7. Crisp, H. L., Gudmundsen, G. R., \& Shirk, S. R. (2006). Transporting evidence-based therapy for adolescent depression to the school setting. Education \& Treatment of Children, 29(2), 287-309.

8. Jacoby, S. F., Tach, L., Guerra, T., Wiebe, D. J., \& Richmond, T. S.(2017).

The health status and well-being of low-resource, housing-unstable, single-parent families living in violent neighbourhoods in Philadelphia, Pennsylvania. Health \& Social Care in the Community, 25 (2), 578-589.

9. Power, T. J., McGoey, K. E., Heathfield, L.T., \& Blum, N. J. (1999). Managing and preventing chronic health problems in children and youth: School psychology's expanded mission. School Psychology Review. 28 (2), 251 - 264. 
10. Roelen, K. (2017). Monetary and multidimensional child poverty: A contradiction in terms? Development and Change, 48(3), 502-533.

11. Slade, N, Eisenhower, A., Carter, A.S., \& Blacher, J. (2018). Satisfaction with individualized education programs among parents of young children with ASD, Eceptional Children, 84 ( 3). 242-260.

12. Smokowski, P. R. (1998). Prevention and intervention strategies for promoting resilience in disadvantaged children. Social Service Review. 72 (3), 337-365

13. The World Bank (2018). Nearly half the world lives on less than $\$ 5.50$ a day. (October 17, 2018). Retrieved from https://www.worldbank.org/en/news/press-release/2018/10/17/nearlyhalf-the-world-lives-on-less-than-550-a-day

14. Ullery,M.A., Gonzalez, A., \& and Katz. L.(2016). Mitigating the effects of poverty and crime: The long-term effects of an early intervention programme for children who were developmentally delayed and prenatally exposed to cocaine. International Journal of Disability Development and Education, 63(4), 403-418.

15. U.S. Census Bureau (2018). Income and poverty in the United States: 2017 (USB report No. P60-263). Retrieved from https://www.census.gov/library/publications/2018/demo/p60263.html

16. Wolfe, S.H., Aron, L. (Ed.). (2013). Health in interenational perspective: Shorter lives, poorer heatlh.Washington, DC: National Academic Pres (US) 